\title{
Isolation for the control of infection in skin wards
}

\author{
By W. C. NOBLE AND PAMELA M. WHITE \\ St John's Hospital for Diseases of the Skin, Institute of Dermatology, \\ Homerton Grove, London E9 6BX
}

(Received 25 February 1972)

\section{SUMMARY}

An isolation policy in a hospital for skin diseases is reported. Patients carrying penicillin- and tetracycline-resistant organisms were to be isolated in single rooms, though barrier nursing was not practised. The policy failed because the single beds rapidly became blocked with long-stay patients and because even in a singlebed unit patients acquired staphylococci within 3-7 days of admission. Patients with skin diseases often do not feel 'ill' and resent isolation.

\section{INTRODUCTION}

Studies on the transmission of micro-organisms, especially Staphylococcus aureus, in wards for patients with diseases of the skin have revealed that such patients are not only prolific sources of organisms but also are more susceptible to colonization and infection than are other patients (Biro et al. 1960; Biro, Gibbs \& Leider, 1960 ; Selwyn, 1963, 1965; Wilson, White \& Noble 1971; Nystrom \& Molin, 1972). Patients with diseases of the skin may suffer sepsis as a result of acquiring organisms in hospital and they may also prove a menace to others (Ayliffe \& Collins, 1967; Payne, 1967). Clinicians feel that skin patients acquiring penicillin and tetracycline resistant organisms more often have their progress retarded than do other patients (Noble, 1970). Finally, although many factors other than purely microbial ones must influence a patient's progress (PHLS, 1960), patients with, for example, psoriasis, who are colonized by Staph. aureus whilst in hospital have a longer stay in hospital than do those not so colonized (Wilson et al. 1971). Finally the works of Hurst \& Grossman (1960) and Wentworth, Miller \& Wentworth (1958) showed clearly that the discharge of patients carrying staphylococci that they had acquired in hospital may result in the appearance of lesions in members of the patients' families. Given the propensity of skin patients to disseminate their organisms this can also be assumed to occur in the families of patients with diseases of the skin.

During the studies reported by Wilson et al. (1971) St John's Hospital for Diseases of the Skin consisted of four open wards each housing 16 or 17 patients with two single-bed side-rooms only. The opportunity was taken during upgrading of these facilities to combine the two male wards and also the two female wards and to reconstruct the interior of one ward for each sex as single rooms although this meant a sacrifice of beds (Fig. 1). Each of the 12 single rooms in each unit is ventilated by extracting air at a rate of $150 \mathrm{ft} .{ }^{3} / \mathrm{min}$. and the central corridor is 


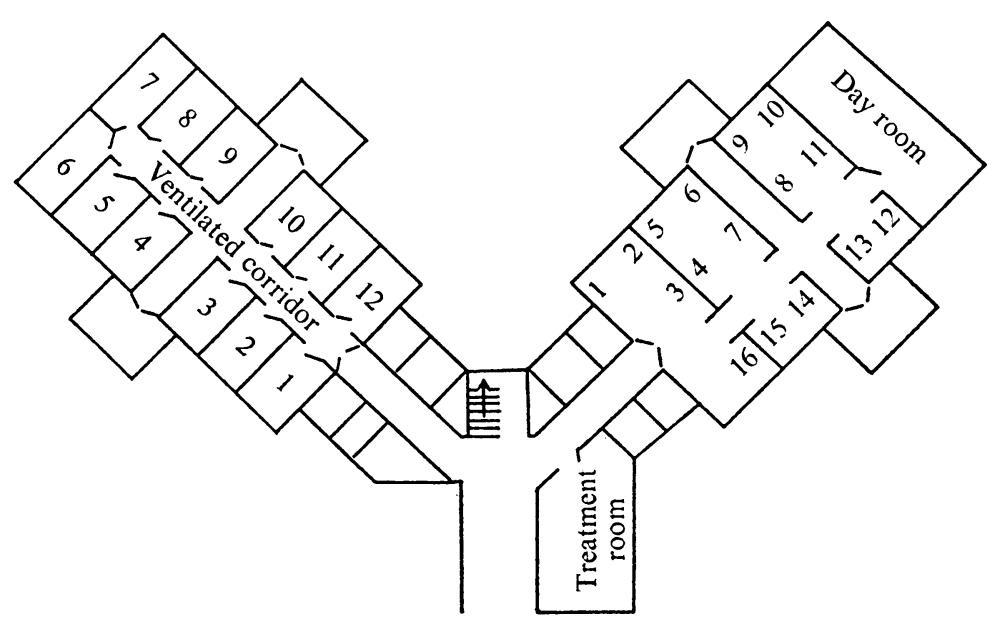

Fig. 1. Plan of ward to show single rooms and open beds.

fed with warmed air filtered to $5 \mu \mathrm{m}$. at $2000 \mathrm{ft} .{ }^{3} / \mathrm{min}$., the temperature of the incoming air being under the control of the ward sister. The open-ward sector of each new unit was reconstructed in enclaves of two or four beds to provide soundbaffling, and a day-room with colour television was completely divided off, where patients could talk, play card-games, etc., and also take their meals.

This seemed a reasonable situation in which to try to isolate patients with 'dangerous' organisms with a view to reducing the transmission of organisms between patients. This paper reports the investigation and its failure.

\section{MATERIALS AND METHODS}

As previously (see Wilson et al. 1971, for details), patients were swabbed in the nose, chest and groin on admission and twice a week thereafter.

In the absence of any known marker of 'dangerous' organisms that could readily be used in an epidemiological investigation, it was decided to isolate patients carrying organisms resistant to both penicillin and tetracycline. Patients were admitted to the single-bed sector and swabbed on, or soon after, admission. Written reports were taken to the ward sister each day and twice a week a complete statement of the carriage state of all patients was prepared for use on the ward. If a patient was found to be free of 'dangerous' organisms at the three control sites and any lesion sites he was moved to the open ward. If carrying 'dangerous' organisms he was left in his single room. Thus a patient free of any Staphylococcus aureus, Pseudomonas or Proteus could be transferred to the open ward within about $24 \mathrm{hr}$. of admission; reports on other patients took longer to prepare when antibiotic sensitivity patterns had to be determined. An exception to the rule was that cutaneous beta-haemolytic streptococci were regarded as 'dangerous' although penicillin-sensitive.

No changes were made in nursing procedures; it is recognized that 'isolation' or 'barrier' nursing requires more staff than open-ward nursing and change in nursing 
procedures was not contemplated in this investigation. However, when the new nursing units were formed a ruling had been laid down that patients in single rooms (for whatever cause) should be nursed in those rooms and all treatments, etc., take place there. Patients in the open sector had their treatments carried out in cubicles in the newly reconstructed treatment room. This policy was of course adhered to in the study. Patients were asked to remain in their rooms with the door shut at all times.

In order to 'start clean', admission of all except emergency cases was stopped until the open sector of the ward unit was free of patients with penicillin- and tetracycline-resistant organisms. The study was carried out twice, first in February/ April 1971 and then December 1971/January 1972, the wards being emptied as far as possible at Christmas as a normal policy. On the first occasion only the male unit took part but on the second occasion both male and female units took part in the study.

\section{RESULTS}

On each occasion the study had to be abandoned, after 2 months on the first occasion and after 3 weeks on the second, because no beds were available in the single-bed rooms, the open sector was empty and the waiting list was growing steadily.

The reasons for this are of interest for the light they shed on isolation policies.

(1) The current hospital staphylococcus is resistant to penicillin, tetracycline, erythromycin, streptomycin and neomycin and is thus classed as a 'dangerous' organism. This organism appears to be very readily acquired by the patients, who become carriers in the nose, chest and groin and doubtless elsewhere and are discharged and may be readmitted still carrying this strain.

(2) Some skin patients are in hospital for long periods; during 1966-8, when 1548 patients were studied, $24 \%$ stayed for more than 4 weeks and $6 \%$ for more than 8 weeks. It is these patients, the most severely affected, who are most at risk and are most likely to acquire hospital staphylococci. Clearly, when this occurs a single room is blocked for a considerable period.

(3) The majority of patients with diseases of the skin do not in themselves 'feel ill'. They resent therefore being denied access to other patients for social contact and resent being unable to use the day-room and view television. Unless senior nursing staff are constantly present they are therefore liable to leave their rooms and go visiting.

These factors combined to prevent the isolation policy from operating. During the 8 weeks of the first period when the scheme was in operation 58 patients were admitted to the 12 beds, though 3 of those were immediately blocked by long-stay patients for the duration of the trial. Twelve of the remaining 55 patients were admitted carrying a penicillin- and tetracycline-resistant organism, usually from a previous admission; a further three were not apparently carriers on admission, but were so within 3 days. Thirty-four patients were transferred to the open sector, where 19 subsequently exhibited a resistant organism, ten within 3 days of transfer, i.e. within about 5-7 days of admission. As a patient known for his ability 


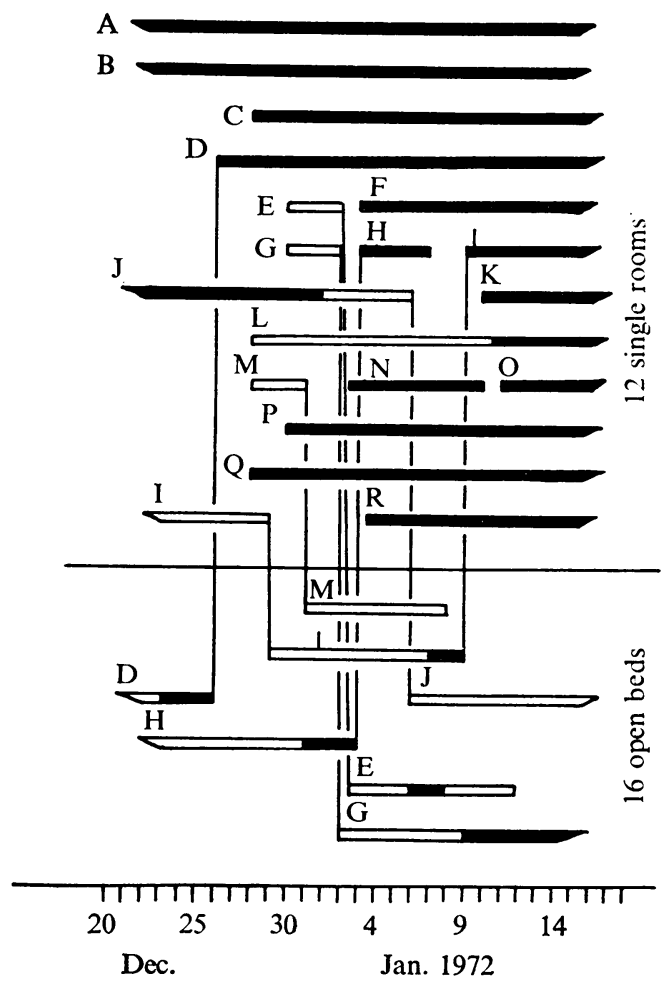

Fig. 2. Diagrammatic representation of male patients' stay in hospital. Bar indicates stay in hospital, black area indicates carriage of penicillin and tetracycline resistant organisms. Vertical lines show transfer of patient between ward sections.

to disperse organisms was one of the three long-stay patients referred to above, it is presumed that he was instrumental in causing at least some of the transmission.

The situation was thus reached in which all single beds were blocked and there were patients in the open sector who also carried resistant organisms. The investigation was abandoned.

During the second period the impasse was reached sooner than before. The result for the male ward is shown diagrammatically (Fig. 2). Four patients in hospital during the Christmas period already carried resistant staphylococci, as did two of the four admitted on 28 December and one of the three admitted on the 30th. All four admitted on 2-3 January, as well as two admitted subsequently, carried resistant staphylococci. There was some acquisition by patients in the open-ward section. The picture in the female ward was essentially the same.

\section{DISCUSSION}

Full and strict isolation can reduce the incidence of acquisition of nasal staphylococci to small proportions (Parker, John, Emond \& Machacek, 1965). In the present investigation it was felt undesirable to insist on strict isolation as skin-patients do not often feel 'ill' and also often have a 'leper' complex regarding their skins - they 
do not like to be thought 'dirty' or 'contaminated'. (It is still a comparatively common belief that skin diseases are somehow a product of dirt or uncleanliness.) Additionally no changes were to be made in the nursing procedures.

Twelve single beds were not sufficient to feed 16 beds in the open sector owing to the propensity of long-stay patients to become colonized and block the beds. This raises important problems in the design of hospital isolation facilities for any area in which severely affected skin patients are to be nursed. There is sufficient evidence to suggest that they should not be put in surgical wards owing to their ability to transmit their flora to other patients (Williams, 1966). It would seem more satisfactory in any subsequent hospital design to construct units of 4-6 beds each but to insist that patients remain in their rooms. In this way patients would not lack company yet would not be exposed to - or be able to donate their microorganisms to - many other individuals.

We are grateful to the Consultant staff of St John's Hospital for Diseases of the Skin for permission to examine the patients bacteriologically, and for supporting this trial; to the nursing staff who tried to work the policy and to Mrs A. El Sherif for technical assistance.

\section{REFERENCES}

Ayliffe, G. A. J. \& Collins, B. J. (1967). Wound infections acquired from a disperser of an unusual strain of Staphylococcus aureus. Journal of Clinical Pathology 20, 195.

Biro, L., Buchbinder, L., Goldberg, S., Pellitteri, O. J. \& Gibbs, R. C. (1960). A staphylococcal disease outbreak in a dermatological service. Bacteriological studies; effect of prior systemic therapy. Archives of Dermatology 82, 740.

Biro, L., Gibis, R. C. \& LeIDer, M. (1960). Staphylococcal infection. A study of incidence on a dermatological ward. Archives of Dermatology 82, 205.

Hurst, V. \& Grossman, M. (1960). The hospital nursery as a source of staphylococcal disease among families of newborn infants. New England Journal of Medicine 262, 951.

NoBle, W. C. (1970). The significance of secondary infection in a skin hospital. Transactions of the St John's Hospital Dermatological Society 56, 26.

Nystrom, B. \& Molin, L. (1972). Colonization with staphylococci in dermatology wards with different designs and practices. British Journal of Dermatology, Supplement no. 8, p. 21.

Parker, M. T., John, M., Emond, R. T. D. \& MachaceK, K. A. (1965). Acquisition of Staphylococcus aureus by patients in cubicles. British Medical Journal i, 1101.

PAYNE, R. W. (1967). Severe outbreak of surgical sepsis due to Staphylococcus aureus of unusual type and origin. British Medical Journal ii, 17.

Public Health Laboratory Service (1960). Incidence of surgical wound infection in England and Wales. Lancet ii, 559.

Selwyn, S. (1963). Bacterial infections in a skin department. British Journal of Dermatology $75,26$.

SELWYN, S. (1965). The mechanism and prevention of cross-infection in dermatological wards. Journal of Hygiene 63, 59.

Wentworth, F. H., Miller, A. L. \& Wentworth, B. B. (1958). Observations relative to the nature and control of staphylococcal disease. American Journal of Public Health 48, 287.

Williams, R. E. O. (1966). Epidemiology of airborne staphylococcal infection. Bacteriological Reviews 30, 660.

Wilson, P. E., White, P. M. \& Noble, W. C. (1971). Infections in a hospital for patients with diseases of the skin. Journal of Hygiene 69, 125. 